\title{
Development of Continuous Surface Wave System For Stiffness Testing
}

\author{
Hidayat Zahari ${ }^{1, \mathrm{~A}}$, Aziman Madun ${ }^{2, \mathrm{~B}}$, Saiful Azhar Ahmad Tajudin ${ }^{3}$, \\ Faizal Tajul Baharuddin ${ }^{4}$, Samsul Haimi Dahlan ${ }^{5}$, \\ Mohd Hazreek Zainal Abidin ${ }^{6}$, and lan Jefferson ${ }^{7}$ \\ ${ }^{1,5}$ Faculty of Electrical and Electronic, Universiti Tun Hussein Onn Malaysia, 86400 Batu Pahat, \\ Johor MALAYSIA. \\ ${ }^{2,3,4,6}$ Faculty of Civil Engineering and Environment, Universiti Tun Hussein Onn Malaysia, 86400 \\ Batu Pahat, Johor MALAYSIA. \\ ${ }^{7}$ School of Civil Engineering, University of Birmingham,UK

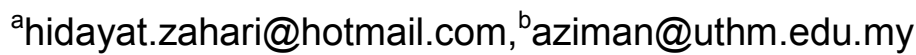

Keywords: continuous surface wave, stiffness, nondestructive test

\begin{abstract}
The measurement of a small strain stiffness can be conducted via measuring the velocity of the material. The stiffness is an indicator for the strength of the material. It is important parameter to understand the response of the material when it received the loads. The seismic surface wave has an advantage technique to measure the stiffness of the materials due to factors of time consuming and non destructive method. In addition, the test can be conducted on the surface of the material, thus ease to conduct the test. The continuous surface wave is using a steady state seismic source which can be controlled it frequency. Thus, sufficient energy at specified frequency can be obtained. This can be influenced the quality and reliability of the data. In addition the stiffness at specified depth can be identified. In this paper, in-house development of the equipment and system was described. A few testing were conducted on different materials in order to assess the reliability of the developed system as well as the stiffness of the materials. As a result, the the stiffness assesment on the concrete mortar, asphalt pavement and concrete wall showed the values were in the range of $0.51 \mathrm{GPa}$ to $0.72 \mathrm{GPa}, 1.39 \mathrm{GPa}$ to $1.76 \mathrm{GPa}$ and $3.48 \mathrm{GPa}$ to $3.78 \mathrm{GPa}$ respectively.
\end{abstract}

\section{Introduction}

Seismic waves are waves of energy that travel through the earth material such as soil or other elastic bodies generated from earthquake, explosion, or some other process that involves the low-frequency acoustic energy. In Civil Engineering, the term of stiffness is referring to the ratio of the stress divided by the displacement which is applied to material or structure. High stiffness means that a large stress produces a small displacement. Stiffness can be defined as the resistance of the body to deformation under applied force [1]. The stiffness parameter at small strain is essential to make predictions of ground movement as well as the quality assesment on the civil material and structure. Traditionally, the measurement of the stiffness profile is carried out by using laboratory and in situ invasive field tests [2][3]. Geophysical methods, such as seismic surface wave techniques, offer a non intrusive and nondestructive approach to measuring very small strain stiffness profiles. Moreover, seismic surface wave approaches provide a cost effective way to measure stiffness parameter. The purpose of analyzing the seismic waves is to obtain the velocity of the wave travelled through the propagation medium. The velocity, then can be transformed to stiffness of the material. Currently, the material stiffness measurement was conducted using the ultrasonic wave technique, which is focused on estimating the overall stiffness. The seismic surface wave technique offers to determine the stiffness in function of depth. In addition, this technique is very suitable for 
inspecting the integrity of the structure of the heritage buildings. In a few cases, the structure deterioration cannot be seen with naked eyes. So to overcome these matters, the non-destructive technique should be adopted to identify the affected areas quickly and in a cost effective way. This surface wave technique had been used by many researchers, in various applications such as in monitoring of soil stiffness during ground improvement using seismic wave [3][4][5] and in surfaces wave velocity methods that are used for determining moduli of the ground in situ at low strain .

\section{Experimental Setup and Procedure}

Based on Fig. 1, source with a piezoelectric transducer are applied on the tested material which is, the mortar to perform the test. An impact source on a surface of tested material is used to generate the Rayleigh waves. The energy of Rayleigh waves from the source propagate mechanically along the surface of media and their amplitude decrease rapidly with depth [6]. The development of more powerful computers for signal processing and for numerical analysis has enabled the CSW method to be more practical [7]. The experiment will be carried out by using computer system with DAQ platform are shown in Fig. 1. The test required a vertically oriented impact source from piezoelectric transducer enabling the generation of Rayleigh wave over a wide frequency bandwidth. The receivers are arranged to be in line with the source are shown in Fig. 1.

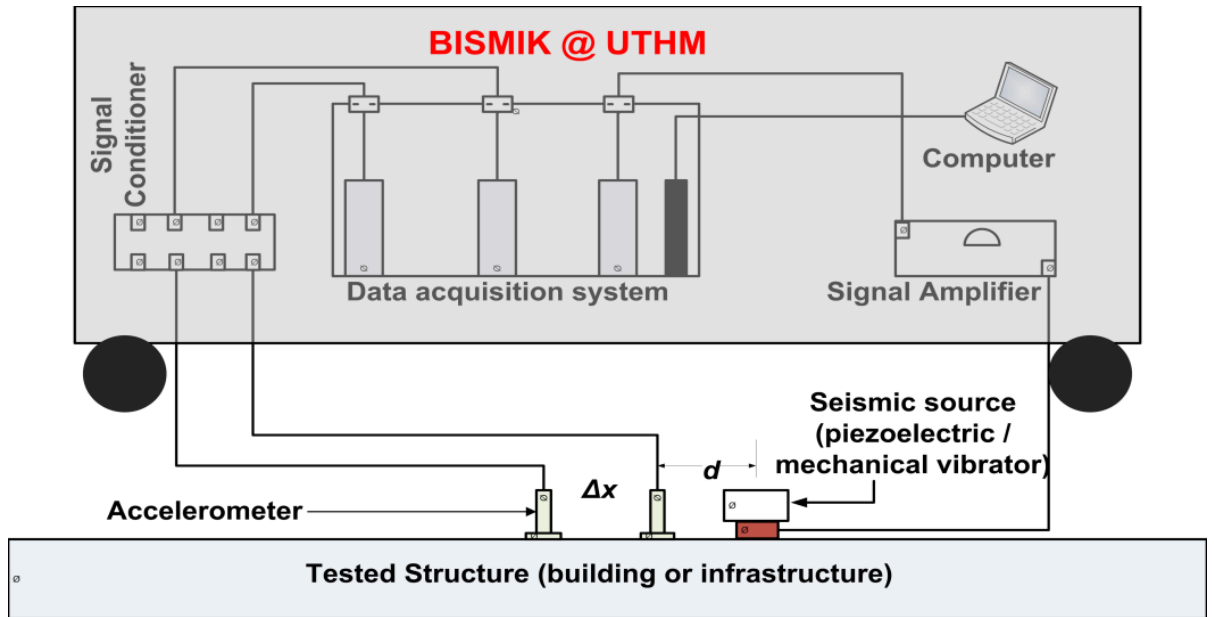

Fig. 1: Hardware setup for data acquisition platform and arrangment of testing

\section{Spectral Analysis of Field Raw Data}

Vertical motion induced by the source at the free surface of the material is detected by the two receivers or accelerometer sensors and recorded in time domain. The data will be transformed using Fast Fourier Transform (FFT) to get the frequency domain and the phase angle to get the phase velocity versus frequency graph of dispersion curves. The signals picked up by the receivers are recorded and Fourier Transformed by using a Fast Fourier Transform (FFT) analyzer to obtain the relative phase between the receivers as a function of frequency [8][9]. When waves travel on the surface material, the frequency signal output will be loss and recorded signal with variation from the source uniformly decreasing in amplitude [8]. Therefore, using higher frequencies implies the increasing of material absorption, thus the field data result lower than the actual signal source because of the signal noise ratio [10]. From the spectral data analysis, the estimation of phase difference between signals from mono frequency source can be made by using a match between the shapes of the waveforms [11].

\section{Sensor Spacing}

The array of receiver consisted of two piezoelectric accelerometers. The receiver array was then moved after each measurement in order to obtain the data for each range between the source and the 
receiver. By using the constraint from the empirical study for the near offset constraint of the distance between the source and the first receiver, $\mathrm{d}_{\min }$ is recommended in the paper [8][11][12] as a function of the surface wave wavelength. Therefore, by assuming the Rayleigh wave phase velocity as $300 \mathrm{~m} / \mathrm{s}$ to $400 \mathrm{~m} / \mathrm{s}$, the applicable frequency range of the piezoelectric transducer was between the $500 \mathrm{~Hz}$ to $10 \mathrm{KHz}$. The excitation from the piezoelectric transducer consisted of $1 \mathrm{~s}$ continuous wave shaded with the hamming window in order to reduce the spectral lobes and increase the dynamic range of the narrow band in interest. By using stepped frequency approach, the frequency was varied with a step size of $100 \mathrm{~Hz}$. For each frequency step, 10 repetitive measurements were obtained for averaging the data collection and make the data more precise and reliable.

\section{Result and Analysis}

The energy introduced by the seismic source needs to control by the tester due to the arrangement and spacing of the receiver itself. Therefore, this may easy to control the constraint such as the upper limit of the frequency and also the useful distance between source and the both receivers. From the CSW testing, this application is the reliable data gathering. The time domain data, has been windowed by using the hamming window which is can increase the signal noise ratio in order to collected and grouped the reliable data of the certain frequency given. Another aspect is the fast capturing data by using the sensor that applicable to capture the signal from $1 \mathrm{~Hz}$ to $10000 \mathrm{~Hz}$ at one $1 \mathrm{~s}$. Therefore, the data taken is more precise at certain frequency. Furthermore, this study has introduced the stepped frequency. By using this approach, it will reduce the time at the field testing work and also at the experiment's laboratory. The control properties of concrete mortar was used as the tested material. The concrete mortar block with dimension of $1.5 \mathrm{~m} \mathrm{x} 1 \mathrm{~m} \times 1 \mathrm{~m}$ (length, width, depth) was casted. The phase velocity can be used as an indicator to calculate the stiffness material by governing the equation of stiffness, shear modulus $=(\text { phase velocity } \times 1.1)^{\wedge} 2 \times$ bulk density [11].

The result at Fig. 2 below shows the graph of phase velocity and stiffness versus wavelength and depth for the concrete mortar, wall and also pavement. The plotted at different receiver spacing was needed to obtain information at different depth. It shows that during the testing when a higher frequency was used, the properties at shallow region layer of the material can be evaluated, and vice versa. Due to the concrete mortar was casted using similar sand and cement ratio, thus it was expected that the phase velocity and stiffness are consistent with the depth.

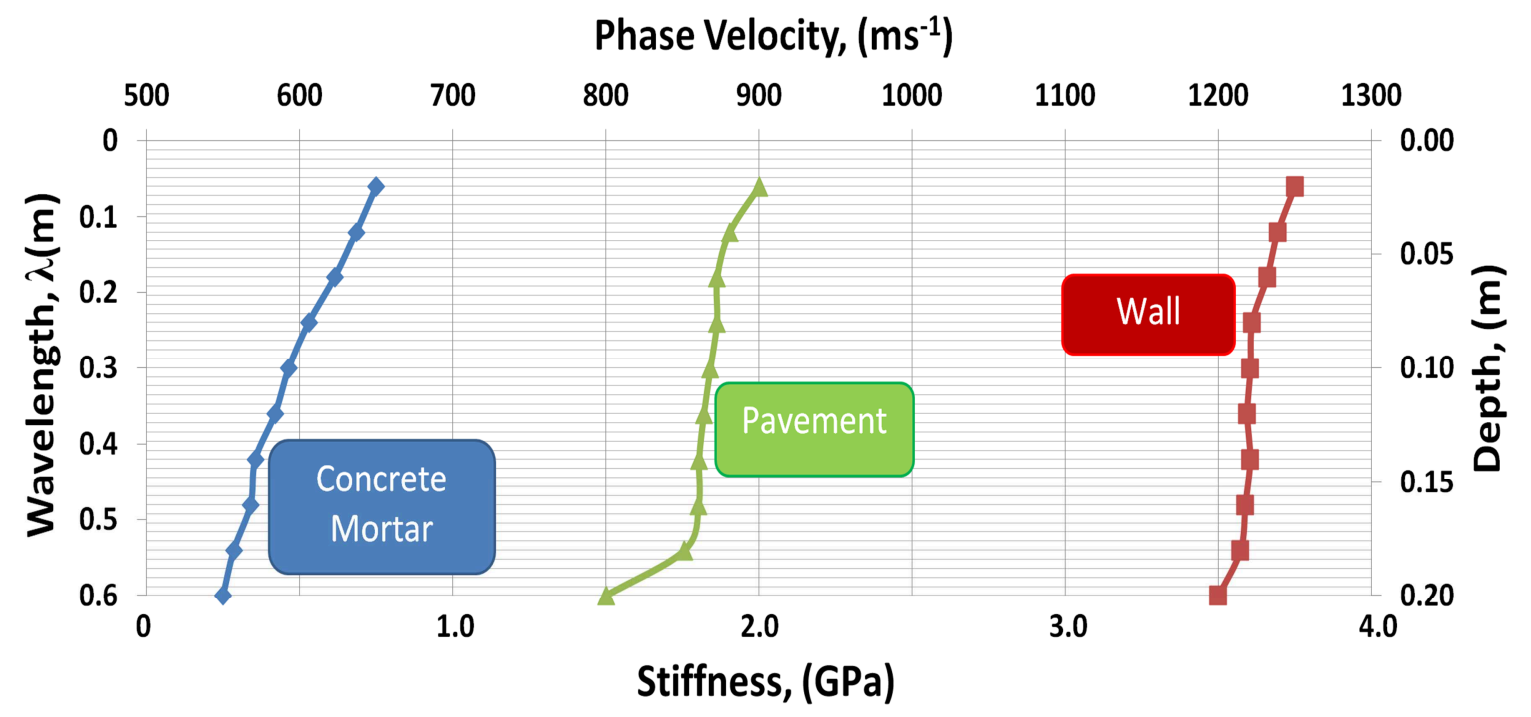

Fig. 2 : Phase velocity and stiffness versus wavelength and depth plot for concrete mortar, pavement and wall 
Moreover, a different type of materials were also tested in order to evaluate the developed testing system. The tests on the asphalt pavement and concrete wall were conducted on the site. The similar experimental procedure and setup starting with frequency between $500 \mathrm{~Hz}$ and $10 \mathrm{KHz}$ and the sensor spacing were varied from $50 \mathrm{~mm}$ to $200 \mathrm{~mm}$. The quality of the seismic data is controlled by the distance of the sensor to the source and the frequency of the wave. In comparison, higher frequency much quicker to attenuate compare to low frequency seismic wave. Thus the distance of the seismic source to sensor controlled the reliable frequency. Due to the continuous seismic surface wave system was conducted using the frequency step, where each 10 repetitive measurements were conducted, thus the reliability of the data can be assessed. Table 1 summarized the range of phase velocity and stiffness results for the different materials.

Table 1: Stiffness and phase velocity result for different materials

\begin{tabular}{ccc}
\hline Material & Phase Velocity, $\mathrm{ms}^{-1}$ & Stiffness, GPa \\
\hline Concrete Mortar & $\mathbf{5 5 0 - 6 5 0}$ & $\mathbf{0 . 5 1 - 0 . 7 2}$ \\
\hline Wall & $\mathbf{1 2 0 0 - 1 2 5 0}$ & $\mathbf{3 . 4 8 - 3 . 7 8}$ \\
\hline Pavement & $\mathbf{8 0 0 - 9 0 0}$ & $\mathbf{1 . 3 9 - 1 . 7 6}$ \\
\hline
\end{tabular}

\section{Conclusion}

As a conclusion, the outcome of this study indicated that the development of the testing system based on CSW technique was able to conduct at different materials. This technique has been conducted on the surface of the material, thus not damaging the material and ease to conduct. By using this technique, the phase velocity and stiffness profile can be determined. By applying windowing function, some signal data might loss, however it helps to obtain the reliable data within the range of the frequency source. The concrete mortar phase velocity was in the range of $550 \mathrm{~ms}^{-1}$ to $650 \mathrm{~ms}^{-1}$ with stiffness between $0.51 \mathrm{GPa}$ and $0.72 \mathrm{GPa}$. Meanwhile in-situ testing on the asphalt pavement and concrete wall were in the range of 1.39 to $1.76 \mathrm{GPa}$ and 3.48 to $3.78 \mathrm{GPa}$ respectively. The phase velocity profiling of the material shows a great potential to measure the small strain stiffness with depth, thus evaluate the quality of the works.

\section{Acknowledgements}

The authors would like to thank the Universiti Tun Hussein Onn, Malaysia, and the Ministry of Education Malaysia, for the research funding grant, FRGS vot. 1061.

\section{References}

[1] C.R.I. Clayton, Stiffness at small strain: research and practise, Geotechnique, 61(1) (2011) 5-37.

[2] A. Madun, I. Jefferson, D.N. Chapman, M.G.Culshaw, K.Y. Foo and P.R. Atkins, Evaluation of the multi-channel surface wave analysis approach for the monitoring of multiple soil-stiffening columns, Near Surface Geophysics, 8(6) (2010) 611-621.

[3] A. Madun, I. Jefferson, K.Y. Foo, D.N. Chapman, M.G.Culshaw and P.R. Atkins, Characterization and quality control of stone columns using surface wave testing, Canadian Geotechnical Journal, vol. 49 (2012) 1357-1368.

[4] A.L. Moxhay, R.D. Tinsley and J.A. Sutton Monitoring of soil stiffness during ground improvement using seismic surface wave. Ground Engineering Magazine, January (2001) 34-37.

[5] B. Luke, Site investigations function better with seismic waves, IEEE Potentials, 18(1), Feb.March (1999) 33-35. 
[6] M.N. Omar, C.P. Abbiss, M.R. Taha and K.A. Mohd Nayan, "Prediction of long-term settlement of soft clay using the continuous surface wave method and damping measurement," In 8th International Conference in Geotechnical and Transportation Geotropika (2010), Sabah 1-3 December 2010.

[7] M. A. Ismail, A. R. Samsudin, A. G. Rafek, and K. A. M. Nayan, "Road Pavement Stiffness Determination using SASW Method," Unimas E-Journal of Civil Engineering, vol. 3(2012), pp. 916.

[8] M.O. Al-Hunaidi, Insight on the SASW non-destructive testing method, Canadian Geotechnical Journal, 20(1993) 940-950.

[9] M.O. Al-Hunaidi, Difficulties with phase spectrum unwrapping in spectral analysis of Surface waves nondestructive testing of pavement, Canadian Geotechnical Journal, 29(3) (1992) 506-511.

[10] B. Piwakowski, A. Fnine, M. Goueygou, and F. Buyle-Bodin, "Generation of Rayleigh waves into mortar and concrete samples," Ultrasonics, vol. 42(2004), pp. 395-402.

[11] M.C. Matthews, Y.S. Hope and C.R.I. Clayton, The use of surface waves in the determination of ground stiffness profiles. Proceedings of the Institution of Civil Engineers Geotechnical Engineering, 119(1996) 84-95.

[12] C.B. Park, R.D. Miller and J. Xia, Multichannel analysis of surface waves. Geophysics 64(1999) 800-808. 